\title{
Short-Wave Near-Infrared Spectroscopy for Rapid Quantification of Acidity of Aviation Kerosene
}

\author{
Zhi-na Xing", Ju-xiang Wang and Gang Shen
}

\author{
Department of Aerocraft Engineering, Naval Aeronautical and Astronautical University, Yantai, China, 264001
}

\begin{abstract}
The application of short-wave near-infrared spectroscopy (SW-NIRS) in acidity of aviation kerosene was described on the term of chemometrics. This spectral region is interesting because this type of spectrometer reduces costs in comparison with traditional long-wave near-infrared (LW-NIR) instrument. The SW-NIR calibration models of aviation kerosene were established by partial least square regression (PLS). Satisfactory calibration statistics were obtained with a standard error of calibration (SEC) of $0.028 \mathrm{mgKOH} / 100 \mathrm{~mL}$ and a standard error of prediction (SEP) of 0.036 $\mathrm{mgKOH} / 100 \mathrm{~mL}$. A $t$-test showed that the NIRS model had an accuracy equivalent to that of GB/T 264-91, which was equal to ASTM D 847, in the analysis of acidity of aviation kerosene. The NIRS method had the advantages of rapid analysis, better repeatability, little simple, and online analysis, etc.
\end{abstract}

Keywords: Aviation kerosene, acidity, short-wave near-infrared spectroscopy (SW-NIRS), rapid quantification.

\section{INTRODUCTION}

Acidity is a significant parameter showing the gross acid content (water-soluble acid and macromolecule organic acid) of aviation kerosene. The acidity expresses the content of macromolecule organic acid normally because aviation kerosene doesn't contain water-soluble acid as leaving factory. Macromolecule organic acid mainly contains naphthenic acid, excessive which may corrode metal material seriously. Then this acidity of aviation kerosene must be determined in time before it is used. While the traditional method (GB/T 264-91, which was equal to ASTM D 847), a typical acidbasetitration, to determine the acidity of aviation kerosene fulfills the necessary requirements of accuracy, specificity, and reproducibility, it is very time-consuming, requiring a plenty of glass apparatuses and multiplicate reagent. In short, it does not meet the need of a rapid, easy to use, selective, and sensitive analytical technique. As a result, a simple and rapid method, which is able to determine the acidity of aviation kerosene accurately in real time, is necessary for the production and use of aviation kerosene.

Near-infrared (NIR) absorption is attributed mainly to overtones and combinations of mid-IR vibrational bands involving $\mathrm{N}-\mathrm{H}, \mathrm{O}-\mathrm{H}$, and $\mathrm{C}-\mathrm{H}$ bonds in molecules [1]. The rich signal information from these groups makes nearinfrared spectroscopy (NIRS) be a useful technique for a lot of organic compounds [2-4]. A few of opportune applications of NIRS in some fuels have been reported $[5,6]$. And NIRS has been used to determined the acid of fruit successully [7-9]. The wavelength range of NIR in the papers above-mentioned was in $1,100-2500 \mathrm{~nm}$ called long-wave NIR (LW-NIR). The spectra information of LW-NIR is rather rich. However the LW-NIR instrument was expensive due to costly detector and light sources. The short-wave NIR

*Address correspondence to this author at the 104 Staff Room, Naval Aeronautical Engineering Institute, Yantai, Shandong Postcard: 264001, China; Tel: 0535-6635574-8006; E-mail: zhnxing2008@163.com
(SW-NIR) situated in region between 700-1,100nm has greatly decreased absorptivities but has the distinct advantages that it can be transmitted over inexpensive fiber optics, can utilize long path lengths $(1-5 \mathrm{~cm})$, and can be measured with very inexpensive light sources (tungsten lamps) and detectors (silicon diode array or silicon charger coupled device, shorted for $\mathrm{CCD}$ ). There are already some documents involved SW-NIR application [10, 11].

The aim of this paper was to describe the manner in which a robust SW-NIRS method to determine acidity was achieved and the results obtained with the new methodology.

\section{EXPERIMENTAL SECTION}

\subsection{Sample Preparation}

Here, 44 samples $(0.09-0.5 \mathrm{mgKOH} / 100 \mathrm{~mL})$ were collected from three different manufactures of aviation kerosene in China. A group of 34 samples was taken to develop an SW-NIR calibration model. The other 10 samples formed a validation set (viz., accuracy set) to test the calibration model.

\subsection{Instrumentation}

NIR spectra were acquired using a NIR- 2000 spectra instrument (Yingxian instrument Co. Ltd., Beijing, China) with a transmission detector (CCD/2048 pixels) with a useable wavelength range of $700-1100 \mathrm{~nm}$. All measurements were performed using a $5 \mathrm{~cm}$ path-length quartz cuvette at an invariable instrument temperature $\left(25 \pm 0.5^{\circ} \mathrm{C}\right)$. Each NIR spectra was the average of 10 scans, using air as reference.

\subsection{Laboratory Reference Method}

All samples were tested for acidity with GB/T 264-91 by the means of the typical acid-basetitration. This was the laboratory reference method for analysis of samples employed as standards for NIRS calibration development. 


\section{RESULTS AND DISCUSSION}

\subsection{Development of a Calibration Model}

Fig. (1) shows the SW-NIRS curve of aviation kerosene. While the basic NIR absorption spectra may be used for calibration purposes, often the centering, 5 points smoothing, and second derivative of the sample spectra are used to remove the influence of random noise, decrease the systematic error, and increase the signal noise ratio (SNR). Second derivatives were obtained using a segment size of 30 and a gap size of 0 .



Fig. (1). NIRS curve of aviation kerosene.

To establish the calibration model from NIR spectra, a stepwise partial least-squares (PLS) regression approach which was provided by the NIR system's software package with the instrument was utilized. The optimal spectral range and model size were then selected on the basis of the minimum prediction residual error sum of squares (PRESS). Full cross-validation following the leave-one-out procedure was performed to determine the optimum number of factors for the model. A certain minimum number of factors were then used to find a suitable calibration. This mode of calibration is not intuitively obvious but can be very useful when fitting curves to complex data patterns. The optimal factor number of this calibration model was 2 which was the factor corresponding to the minimum prediction residual error sum of squares (PRESS) in Fig. (2).

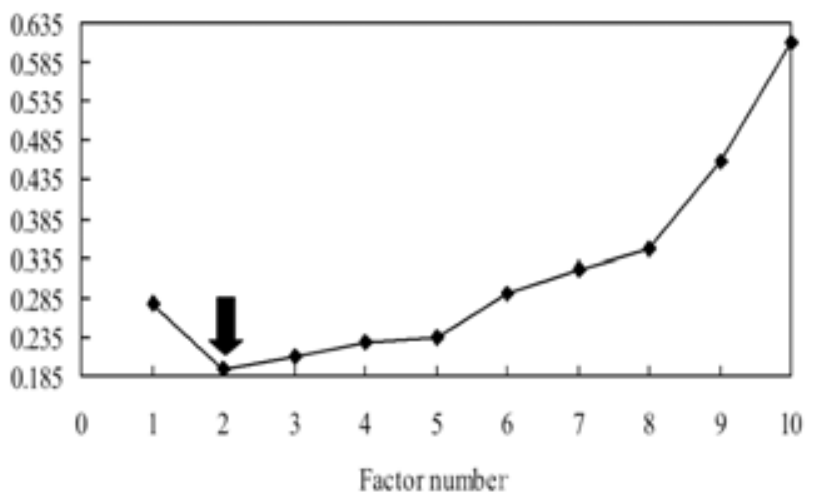

Fig. (2). Effect of factor number on PRESS.
Table 1 showed the parameters of the calibration model. The correlation between the reference values calculated from GB/T 264-91 analyses and the predicted values received from the NIRS calibration model was shown in Fig. (3). The variation data was good for most of the criteria under investigation.



Fig. (3). NIR prediction versus reference determination $(\mathrm{n}=34)$. $\mathrm{R}^{2}=0.9001 ; \mathrm{SEC}=0.028 \mathrm{mgKOH} / 100 \mathrm{~mL}$.

\subsection{Validation of Accuracy}

The 10 samples belonging to the validation set were chosen in order to test the accuracy of the calibration model. The accuracy samples encompassed an acidity range of 0.11-0.43 $\mathrm{mgKOH} / 100 \mathrm{~mL}$. A comparison of the values reported by the SW-NIR method with those of the laboratory reference method was presented in Table 2 . This difference between these two methods was statistically significant at the $95 \%$ confidence $(\alpha=0.05)$ level because tcalculation values $=0.266$ were below ttalbe $=2.365$. This result underscored the importance of the validation of method accuracy with an independent set of samples prior to routine use of the method. The standard error of prediction (SEP) between the SW-NIR values and the laboratory reference values was $0.036 \mathrm{mgKOH} / 100 \mathrm{~mL}$ which was far less than the reproducibility of GB/T 264-91 $=0.15 \mathrm{mgKOH} / 100 \mathrm{~mL}$.

\subsection{Precision of the Calibration Model}

To demonstrate the repeatability of the NIR method, a single sample of aviation kerosene was analyzed seven times repeatedly. Table 3 summarized the data obtained for replicate analysis of it, along with the expected "true" value. It was evident, given the low standard deviation values, that this method performed well during replicate testing with high precision.

\section{CONCLUSIONS}

In the present study, it was verified that the SW-NIR spectrometer, where the use of less expensive instruments is possible, can be used to quantify the acidity of aviation kerosene with precision similar to GB/T 264-91. The PLS calibration model developed on 34 different aviation kerosene

Table 1. Parameters of Models

\begin{tabular}{|c|c|c|c|c|}
\hline $\begin{array}{c}\text { Modeling Regression } \\
\text { Band (nm) }\end{array}$ & Spectra Pretreatment & Optimal Factor & $\begin{array}{c}\text { Standard Error of Calibration } \\
\text { (SEC) } \mathbf{m g K O H} / \mathbf{1 0 0 m L}\end{array}$ & $\begin{array}{c}\text { Min PRESS Value } \\
\mathbf{m g K O H} / \mathbf{1 0 0 m L}\end{array}$ \\
\hline \hline $817 \sim 1045$ & $\begin{array}{c}5 \text { points smoothing centering, } \\
\text { Second derivative (30) }\end{array}$ & 2 & 0.028 & 0.1944 \\
\hline
\end{tabular}


Table 2. Comparison of Results Determined by NIRS and GB/T 264-91 Method (mgKOH/100mL)

\begin{tabular}{|c|c|c|c|c|c|c|c|}
\hline NO. & GB/T 264-91 & NIRS & Error & SEP & Reproducibility of GB/T 264-91 & $t_{\text {calculation }}$ & $t_{\text {talbe }}$ \\
\hline 1 & 0.22 & 0.25 & -0.03 & \multirow{10}{*}{0.036} & \multirow{10}{*}{0.15} & \multirow{10}{*}{0.266} & \multirow{10}{*}{2.365} \\
\hline 2 & 0.43 & 0.39 & 0.04 & & & & \\
\hline 3 & 0.28 & 0.24 & 0.04 & & & & \\
\hline 4 & 0.26 & 0.27 & -0.01 & & & & \\
\hline 5 & 0.22 & 0.19 & 0.03 & & & & \\
\hline 6 & 0.18 & 0.21 & -0.03 & & & & \\
\hline 7 & 0.32 & 0.37 & -0.05 & & & & \\
\hline 8 & 0.39 & 0.38 & 0.01 & & & & \\
\hline 9 & 0.34 & 0.29 & 0.05 & & & & \\
\hline 10 & 0.11 & 0.13 & -0.02 & & & & \\
\hline
\end{tabular}

Table 3. Precision of Correction Model $(\mathrm{mgKOH} / 100 \mathrm{~mL})$

\begin{tabular}{|c|c|c|c|c|}
\hline $\begin{array}{l}\text { Determination Times } \\
\text { of SW-NIRS }\end{array}$ & SW-NIRS & $\begin{array}{c}\text { Reference Value of } \\
\text { GB/T 264-91 }\end{array}$ & $\begin{array}{l}\text { Standard Deviation } \\
\text { of Replicates }\end{array}$ & $\begin{array}{c}\text { Reproduction } \\
\text { of GB/T 264-91 }\end{array}$ \\
\hline 1 & 0.23 & \multirow{7}{*}{0.22} & \multirow{7}{*}{0.016} & \multirow{7}{*}{0.15} \\
\hline 2 & 0.23 & & & \\
\hline 3 & 0.24 & & & \\
\hline 4 & 0.24 & & & \\
\hline 5 & 0.21 & & & \\
\hline 6 & 0.2 & & & \\
\hline 7 & 0.22 & & & \\
\hline
\end{tabular}

samples had a R2 value of 0.9001 with a standard error in the fit of $0.028 \mathrm{mgKOH} / 100 \mathrm{~mL}$. The SEP and the precision of this method was estimated to be 0.036 and 0.016 $\mathrm{mgKOH} / 100 \mathrm{~mL}$ respectively. The difference of the set of 10 accuracy samples between NIRS and GB/T 264-91 was statistically significant at the $95 \%$ confidence level. In comparison to GB/T 264-91 procedures, SW-NIRS has the distinct advantages of being much faster, requiring less or no chemicals at all and no sample preparation. Thus, not only is the cost of analysis considerably reduced, but the environmental and safety concerns were also met.

\section{REFERENCE}

[1] Skoog D.A.; Holler J.F.; Nieman T.A. Principles of instrumental analysis, $5^{\text {th }}$ Ed. Saunders College Pub.: Philadelphia, 1998, pp 422-430.

[2] Osbome B.G. Practical NIT Spectroscopy with Applications in Food and Beverage Analysis An imorint of Pearson Education, Second Ed., 1993, pp. 28-33.

[3] Wan-Zhen, L.; Hong-Fu, Y.; Guang-Tong, X. Modern NIRS analysis technology, petroleum publishing company: China, 2000, vol. 4, pp. 146-147.
[4] Judge, M.D. The application of near-infrared spectroscopy for the quality control analysis of rocket propellant fuel pre-mixes, $J$. $\mathrm{Ta}$ lanta, 2004, 62, 675 .

[5] Vogelsanger, B.; Ossola, B. Proceeding of 31st International Annual Conference of ICT, Karlsruhe, Germany, 2000, 5-1-5-13.

[6] Zhi-Na, X.; Ju-Xiang, W.; Yong, Y.; Gang, S. Rapid quantification of kinematical viscosity in aviation kerosene. J. Energy Fuels, 2006, 20, 2486.

[7] Yan-De, L.; Yi-Bin, Y.; Xia-Ping, F. Rapid quantification of kinematical viscosity in aviation kerosene. J. Spectrosc. Spectral. Anal., $\mathbf{2 0 0 5}, 25,1793$.

[8] Shao, Y.; He, Y. Nondestructive measurement of the internal quality of bayberry juice using Vis/NIR spectroscopy. J. Food Eng., 2007, 79, 1015.

[9] Liu, Y.D.; Ying, Y.B.; Jiang, H.Y. Rapid determination of maturity in apple using outlier detection and calibration model optimization, J. Trans. ASABE, 2006, 49, 91.

[10] Barboza, F.D.; Poppi, R.J. Determination of alcohol content in beverages using short-wave ear-infrared spectroscopy and temperature correction by transfer calibration procedures. J. Anal. Bioanal. Chem., 2003, 377, 695.

[11] Kelly, J.J.; Callis, J.B. Nondestructive Analytical procedure for simultaneous estimation of the major lasses of hydrocarbon constituents of finished gasolines. J. Anal. Chem., 1990, 62, 1444.

(C) Xing et al.; Licensee Bentham Open.

This is an open access article licensed under the terms of the Creative Commons Attribution Non-Commercial License (http://creativecommons.org/licenses/by$\mathrm{nc} / 3.0 /$ / / which permits unrestricted, non-commercial use, distribution and reproduction in any medium, provided the work is properly cited. 